\title{
VARIÁVEIS DE BURNOUT EM PROFISSIONAIS DE UMA UNIDADE DE EMERGÊNCIA HOSPITALAR
}

\author{
Eliane Raquel Rieth Benetti¹, Eniva Miladi Fernandes Stumm², Fernanda Izolan³ ${ }^{3}$ Liliane Pereira Ramos ${ }^{4}$, Rosane Maria
}

Kirchner $^{5}$

RESUMO: Esta pesquisa busca identificar e comparar variáveis que caracterizam a Síndrome de Burnout, presentes nos profissionais de uma Unidade de Emergência de um hospital da região noroeste do Rio Grande do Sul. É quantitativa, analítica, descritiva, envolvendo 31 profissionais. Para a coleta de dados utilizaram-se dois questionários, sendo analisados com estatística descritiva. Os escores das três dimensões da Síndrome de Burnout: Desgaste Emocional, Despersonalização e Incompetência, indicam baixo nível de Burnout. Comparativamente, a equipe médica apresentou média mais alta no Desgaste Emocional do que a enfermagem. Nas variáveis presentes no Contexto do Trabalho (quantitativo), Sobrecarga de Trabalho, Desenvolvimento da Carreira e Estrutura Organizacional, evidenciam-se sintomas da síndrome.

PALAVRAS-CHAVE: Equipe de enfermagem; Médicos; Serviços médicos de emergência; Esgotamento profissional.

\section{BURNOUT VARIABLES IN PROFESSIONALS OF AN EMERGENCY HOSPITAL UNIT}

\begin{abstract}
In this study we want to identify and compare the variables that qualify the Burnout Syndrome that are present among professionals from an Emergency Unit in a hospital in the northwest region of Rio Grande do Sul, Brazil. It is a quantitative, analytical and descriptive study, involving 31 professionals. Data were collected using two questionnaires, that were analyzed through descriptive statistics. The scores of the three Burnout Syndrome dimensions: emotional waste, depersonalization, incompetence, indicate low Burnout level. Comparing the physicians team and the nursing, the first one had a higher average on emotional waste than the second one. The syndrome symptoms could be evidenced on the variables presented on the Work Context (quantitative), Work Overload, Careers Development and Organizational Structure.

KEYWORDS: Nursing team; Physicians; Emergency medical services; Burnout; Professional depletion.
\end{abstract}

\section{VARIABLES DEL BURNOUT EN PROFESIONALES DE UNA UNIDAD DE EMERGENCIAHOSPITALARIA}

RESUMEN: Esta investigación busca identificar y comparar variables que caracterizan el Síndrome de Burnout, presentes en los profesionales de una Unidad de Emergencia de un hospital de la región noroeste del estado de Rio Grande del Sur. Es cuantitativa, analítica, descriptiva, envolviendo 31 profesionales. Para la colecta de los datos fueran utilizados dos cuestionarios, siendo analizados con estadística descriptiva. Los resultados de las tres dimensiones del Síndrome de Burnout: Desgaste Emocional, Despersonalización e Incompetencia, indican bajo nivel de Burnout. De forma comparativa, el equipo médico presentó promedio más alto en el Desgaste Emocional que el equipo de enfermería. En las variables presentes en el Contexto del Trabajo (cuantitativo), Sobrecarga de Trabajo, Desarrollo de la Carrera y Estructura Organizacional, se presentan síntomas del síndrome.

PALABRAS CLAVE: Equipo de enfermería; Médicos; Servicios médicos de emergencia; Agotamiento profesional.

\footnotetext{
${ }^{1}$ Enfermeira do Pronto Atendimento e Nefrointensivismo do Hospital Unimed Ijuí-RS. Especialista em Urgência, Emergência e Trauma pela Universidade Regional do Noroeste do Estado do Rio Grande do Sul-UNIJUÍ. Pós-Graduanda em Nefrologia Interdisciplinar pelo Instituto de Educação em Pesquisa, Hospital Moinhos de Vento-POA/RS.

${ }^{2}$ Enfermeira. Mestre em Administração - Recursos Humanos pela Universidade Federal do Rio Grande do Sul-UFRGS. Docente da UNIJUÍ.

${ }^{3}$ Enfermeira. Enfermeira Supervisora Noturna do Hospital do Coração de Balneário Camboriú/SC. Especialista em Urgência, Emergência e Trauma pela UNIJUÍ.

${ }^{4}$ Enfermeira. Hospital Unimed Ijuí/RS. Especialista em Urgência, Emergência e Trauma pela-UNIJUÍ.

${ }^{5}$ Doutora em Engenharia Elétrica - Métodos de Apoio à Decisão. Docente da UFSM-UNIPAMPAS, São Gabriel.
}

Autor correspondente:

Eliane Raquel Rieth Benetti

Rua do Comércio, 2323 - 98700-000 - Ijuí-RS

E-mail: elianeraquelr@yahoo.com.br

Recebido: 18/11/08 Aprovado: 15/06/09 


\section{INTRODUÇÃO}

Trabalhar em emergência nem sempre é prazeroso, diante do cenário da prestação de serviços em saúde, a cada dia mais complexo. A escassez de recursos aliada à exigência de contenção de custos e otimização do tempo de permanência são fatores que favorecem o estresse e o desgaste do profissional. Os profissionais do setor de emergência são submetidos, constantemente, à sobrecarga de trabalho mental, psíquica e física, além de pressão para tomada de decisões rápidas, fundamentais no atendimento de emergência ${ }^{(1)}$. Ainda, as jornadas de trabalho são extenuantes, dado o volume de usuários e a reposição de energia desses trabalhadores nem sempre é adequada.

A equipe se depara com diversas situações, aliadas à necessidade de saber lidar, de forma eficiente e eficaz, com as necessidades do usuário. Os profissionais convivem com os mais diversos agravos à saúde, envolvendo dor, sofrimento, instabilidade, morte e vida, contribuindo para a ocorrência de ansiedade, tensão, podendo evoluir para o estresse. O estressor é definido como uma situação ou experiência que gera sentimentos de tensão, ansiedade, medo ou ameaça, que pode ter origem interna ou externa ${ }^{(2)}$. Assim, o estresse é um fenômeno complexo e dinâmico, merecedor de atenção especial dos profissionais da saúde, tendo a clareza de que "por mais que a subjetividade e a percepção sejam pioneiras no desencadeamento de estresse, as condições de trabalho exercem influência significativa para seu agravo”(3:32).

A Síndrome de Burnout se diferencia do estresse porque compreende atitudes e comportamentos negativos em relação ao trabalho e às pessoas envolvidas neste contexto, sendo que a dificuldade é de ordem emocional. O estresse, por sua vez, trata-se de um esgotamento pessoal que prejudica o indivíduo, mas não necessariamente decorre de sua relação com o trabalho $^{(4)}$. O Burnout é resultante do estresse crônico vivenciado pelo profissional no ambiente de trabalho e não se relaciona jamais com sentimentos positivos, o que pode acontecer com o estresse.

Burnout é um problema que atinge profissionais de serviço, principalmente aqueles voltados para atividades de cuidado com outros, no qual a oferta deste serviço, frequentemente, ocorre em situações de mudanças emocionais ${ }^{(5)}$. Cuidar sempre foi reconhecido como atividade nobre, entretanto, pouca atenção tem sido dada ao desgaste emocional oriundo deste ofício.
As principais causas para a ocorrência de Burnout em profissionais da saúde são: o contato contínuo com o sofrimento, a dor e a morte; a diminuição do valor social do profissional pela sua família; a sobrecarga de trabalho; a carência de recursos para desempenhar o papel adequadamente; a diminuição nos diversos tipos de recompensa e estímulos em sua atividade; a inquietação e ameaça de sofrer críticas por mau desempenho de sua prática laboral e encarar problemas éticos resultantes do avanço tecnológico(6).

Importante ressaltar que o uso do termo Burnout funciona como metáfora para explicar que se chegou ao limite de esforço, e que, devido à falta de energia, não há mais condições físicas nem mentais para trabalhar. Trata-se de uma síndrome tridimensional, caracterizada por três componentes: Exaustão Emocional, Incompetência e Despersonalização( ${ }^{(7)}$. O primeiro componente refere-se a sentimentos de fadiga e redução dos recursos emocionais necessários para lidar com a situação estressora, ou seja, frustração e tensão no trabalho; o segundo à percepção de deterioração da auto-competência e falta de satisfação com as realizações e o sucesso de si próprio no trabalho, fazendo com que o indivíduo se perceba de forma negativa em seu trabalho. O terceiro componente relaciona-se a atitudes negativas, descrença, insensibilidade e despreocupação com respeito a outras pessoas. Geralmente troca-se o vínculo afetivo pelo racional.

O cuidado em enfermagem está diretamente ligado ao envolvimento e ao comprometimento da pessoa com a instituição e com a profissão. A pessoa deve sentir que é um trabalho que vale a pena ser feito, que reforça sua auto-imagem e que contribui para que ela se perceba parte de um processo maior ${ }^{(8)}$. O trabalho médico, por sua própria natureza e a de seu objeto de trabalho - o contato com a dor, o sofrimento e a morte do paciente - é uma atividade desgastante, não apenas em condições de venda da força produtiva dos médicos para terceiros, em que se extrai "mais-valia" deste trabalhador da saúde, mas também na produção exercida de forma liberal e autônoma, em consultórios particulares ${ }^{(9)}$.

Os profissionais que atuam em emergência se deparam com situações que envolvem risco de morte e os procedimentos diagnósticos e terapêuticos são merecedores de monitoramento contínuo, aliado a decisões adequadas e rápidas. Eles se angustiam diante das inúmeras atribuições, contribuindo para o conflito relacionado ao sentimento de sobrecarga e o 
cumprimento das mesmas ${ }^{(10)}$.

O trabalho em hospital requer dos profissionais experiência clínica, maturidade, estabilidade emocional, permitindo enfrentar e tomar decisões difíceis envolvendo, inclusive, questões éticas e morais. Estes profissionais estão expostos a diferentes estressores, que afetam seu bem estar e, o fato de lidar com pessoas em estado grave, compartilham com elas e seus familiares a angústia, a dor, a depressão e o medo de padecerem $^{(11)}$.

Paralelamente a esse cenário, há um aumento da demanda de serviços nas emergências e, com isso, algumas dificuldades dos profissionais em levar seu trabalho a termo. Observam-se manifestações de cansaço, abatimento, conflitos e diminuição da satisfação com suas atividades, sendo visível o sofrimento psíquico, que pode evoluir para o estresse e contribuir para a ocorrência de Burnout.

Considerando esse cenário, a presente pesquisa busca identificar e comparar as variáveis que caracterizam a Síndrome de Burnout, presentes nos profissionais que atuam em uma Unidade de Emergência de um hospital da região noroeste do Rio Grande do Sul.

\section{METODOLOGIA}

O estudo é quantitativo, analítico, descritivo, tipo estudo de caso, envolvendo todos os profissionais da saúde (33) que atuam na Unidade de Emergência de um hospital geral, privado, da região noroeste do Estado do Rio Grande do Sul. A população compreende: 14 técnicos em enfermagem, 1 auxiliar de enfermagem, 6 enfermeiros e 12 médicos. Todos aceitaram participar, porém dois profissionais não devolveram os instrumentos devidamente preenchidos, sendo então, excluídos.

A Unidade de Emergência, local de realização da pesquisa, é a porta de entrada do referido hospital, funcionando 24 horas. Situa-se, estrategicamente, ao lado do Centro de Diagnóstico por Imagem, facilitando a realização de exames radiológicos com rapidez, em casos de urgência/emergência, além de possuir acesso facilitado ao Centro de Tratamento Intensivo e Centro Cirúrgico. Dispõe de uma área física ampla, com oito leitos de observação e a sala de emergência possui dois acessos, um principal e um secundário.

Os instrumentos de coleta dos dados foram o “Inventário de Burnout de Maslach”(12), validado por Lautert $^{(13)}$, composto por 52 perguntas fechadas, com grau de intensidade/frequência para a resposta e um questionário criado e testado pelas pesquisadoras, contendo dados de identificação e sociodemográficos.

Previamente, foi solicitada autorização ao administrador do referido hospital para a coleta de dados. Após parecer positivo da instituição, o projeto de pesquisa foi registrado no SISNEP e encaminhado ao Comitê de Ética em Pesquisa da Universidade Regional do Noroeste do Rio Grande do Sul, sendo aprovado sob o Parecer Consubstanciado n ${ }^{\circ}$ 080/2007. Após aprovação do projeto de pesquisa por essas instâncias, procedeu-se a coleta de dados.

Os dados foram analisados com o auxílio do software estatístico SPSS/7.5 e estatística descritiva, envolvendo as medidas de tendência central e de variabilidade. Os dados são apresentados em forma de tabelas e/ou figuras que representem de maneira clara os resultados obtidos, favorecendo a análise e discussão dos mesmos.

Para a análise quantitativa das variáveis que caracterizam a Síndrome de Burnout, adotou-se a escala do tipo Likert, considerando que os valores da escala de respostas encontravam-se num intervalo de 1 a 5 , sendo 1 para "nunca", 2 "algumas vezes ao ano”, 3 “algumas vezes ao mês", 4 "algumas vezes na semana” e 5 para "diariamente" ${ }^{(12)}$. Foram consideradas as análises dos dados coletados por meio das médias dos escores de cada fator para todos os profissionais.

Vale ressaltar que a direção dos escores da escala Incompetência é oposta à dos escores das escalas Desgaste e Despersonalização. A avaliação dos índices de Burnout ocorre de acordo com os escores de cada dimensão, sendo que altos escores em Desgaste Emocional e Despersonalização e baixos escores em Incompetência (sub-escala inversa), indicam alto nível de Burnout ${ }^{(14)}$. A partir da pontuação mencionada, foi possível calcular média, variância, desvio padrão e o coeficiente de variação.

\section{RESULTADOS E DISCUSSÃO DOS DADOS}

Analisando os dados de caracterização e sociodemográficos dos profissionais que integraram a pesquisa, evidencia-se que os homens representam $51,6 \%$ e as mulheres $48,4 \%$. Relacionando esse resultado à Síndrome de Burnout, o gênero feminino apresenta maiores índices de Exaustão Emocional, enquanto o masculino tem elevados escores de Despersonalização ${ }^{(7)}$.

No que diz respeito ao estado civil, mais da 
metade dos profissionais são casados (58,1\%), 25,8\% são solteiros e $16,1 \%$ são separados. Normalmente, sujeitos casados ou que vivenciam uma união estável possuem menor propensão ao Burnout ${ }^{(7)}$. Dessa forma, os escores mais elevados da síndrome aparecem em solteiros, viúvos ou divorciados. Entretanto, a autora se reporta não só a importância de um relacionamento, mas a qualidade do mesmo como fator de influência para o surgimento ou não da referida síndrome.

Quanto à distribuição dos profissionais por faixa etária, observa-se que grande parte deles é de jovens, sendo que o maior percentual (35,5\%) possui entre 25 e 30 anos e apenas 3,2\% (1) mais de 50 anos. A relação entre as dimensões de Burnout e variáveis demográficas apontam que quanto mais jovens os profissionais, maior é a Exaustão Emocional. Isso ocorre devido ao entendimento irrealístico sobre o que podem ou não fazer, portanto, são frequentes as frustrações profissionais nesta fase da vida ${ }^{(14)}$.

Em relação ao tempo de atuação no referido hospital, a maioria $(77,4 \%)$ dos profissionais trabalha desde a abertura da instituição, há dois anos, sendo que $54,8 \%$ com exclusividade. Haja vista que a instituição não exige exclusividade de seus colaboradores e, relacionando este item com a categoria profissional, constata-se que os médicos, em sua totalidade, atuam em dois ou mais empregos, o que os diferencia dos profissionais de enfermagem.

Quanto à escolha dos pesquisados por trabalhar na área, a grande maioria $(87,1 \%)$ optou em desenvolver suas atividades profissionais na Unidade de Emergência. Neste sentido, sujeitos altamente motivados quanto à sua profissão são mais suscetíveis ao Burnout ${ }^{(15)}$.
Constata-se que a maior parte dos pesquisados $(83,4 \%)$ possui entre 1 e 10 anos de experiência em emergência e 16,6\% mais de 10 anos. Pode-se interpretar o Burnout tanto como conseqüência de um desgaste incrementado pelo tempo de profissão, quanto um fenômeno decorrente da falta de experiência na profissão e, após o primeiro ano trabalhando em uma instituição, os sujeitos estarão predispostos a desenvolver Burnout ${ }^{(7)}$.

Quanto à formação profissional dos participantes da pesquisa, 48,4\% são especialistas (médicos e enfermeiros), 9,7\% são graduados (enfermeiros) e 41,9\% possuem o ensino médio (técnicos e auxiliar em enfermagem). Pode-se afirmar que eles valorizam o aperfeiçoamento profissional, uma vez que dentre os que possuem ensino superior, 83,3\% possuem especialização em sua área de atuação.

A seguir é apresentada a análise do Inventário de Burnout de Maslach-MBI ${ }^{(13)}$, buscando evidenciar as características presentes nas duas equipes de profissionais pesquisadas. O referido instrumento é utilizado, exclusivamente, para a avaliação da referida síndrome, não levando em consideração os elementos antecedentes nem as conseqüências resultantes de seu processo.

$\mathrm{Na}$ Tabela 1, considerando todos os trabalhadores da referida unidade, os escores obtidos foram baixos nas primeiras duas dimensões e elevados na Incompetência (escore reverso), evidenciado nas médias, indicando baixo nível de Burnout nos sujeitos da pesquisa. Ainda, destaca-se a homogeneidade das respostas, isto é, não houve grande oscilação nas respostas, confirmada pelo coeficiente de variação menor de $30 \%$.

Tabela 1 - Estatística descritiva do inventário de Burnout de Maslach. Ijuí, 2007

\begin{tabular}{lccccccccc}
\hline Escala de conversão & \multicolumn{3}{c}{ Média } & \multicolumn{4}{c}{ Desvio padrão } & \multicolumn{3}{c}{ CV (\%) } \\
\hline Equipe & Geral & Enfer. & Médica & Geral & Enfer. & Médica & Geral & Enfer. & Médica \\
\hline Desgaste Emocional & 1,99 & 1,800 & 2,358 & 0,31 & 0,334 & 0,486 & 15,62 & 18,58 & 20,60 \\
Despersonalização & 1,61 & 1,622 & 1,580 & 0,45 & 0,496 & 0,528 & 28,22 & 30,60 & 33,42 \\
Incompetência & 4,58 & 4,568 & 4,588 & 0,25 & 0,264 & 0,329 & 5,40 & 5,79 & 7,17 \\
\hline
\end{tabular}

Incompetência com escore reverso CV: Coeficiente de variação

O Desgaste Emocional é o traço fundamental da Síndrome de Burnout e caracteriza-se por um sentimento forte de tensão emocional, que produz sensação de esgotamento, de falta de energia e de recursos emocionais próprios para lidar com as rotinas da prática profissional. Ele representa a dimensão individual da síndrome. Assim, na medida em que os recursos emocionais vão se deteriorando, a pessoa acometida sente gradativa redução de sua capacidade e vigor para o trabalho(16). Em relação à Despersonalização ou Desumanização, ela se caracteriza por cinismo e dissimulação afetiva, e o 
trabalhador manifesta ansiedade, irritabilidade excessiva e ausência de motivação ${ }^{(15)}$.

Os profissionais da saúde são considerados vulneráveis ao Burnout, tanto pelas características inerentes à profissão, pela intensidade das interações emocionais e pela falta de tempo livre para lazer, férias, quanto pelas modificações do mundo do trabalho. Neste contexto, pensa-se que podem existir variáveis da referida síndrome, comuns às duas equipes, porém com intensidades diferentes, analisadas a partir de agora, em caráter comparativo.

Na análise comparativa entre as duas categorias profissionais (Tabela1), o escore de desgaste emocional foi mais elevado na equipe médica, com uma média de 2,36, com uniformidade de respostas, representada pelo desvio padrão de 0,49 e coeficiente de variação de $20,60 \%$. Pode-se afirmar, a partir dos resultados obtidos, que os médicos da unidade pesquisada apresentam um nível médio de desgaste emocional. Já, na equipe de enfermagem, esta característica apresenta uma média de 1,80 com desvio padrão de 0,33 e coeficiente de variação de 18,58\%, representando um nível baixo de desgaste emocional. Para visualizar de forma mais clara e comparativa os escores, eles são representados na Figura 1, onde se verifica o intervalo da média com mais e menos um desvio padrão.

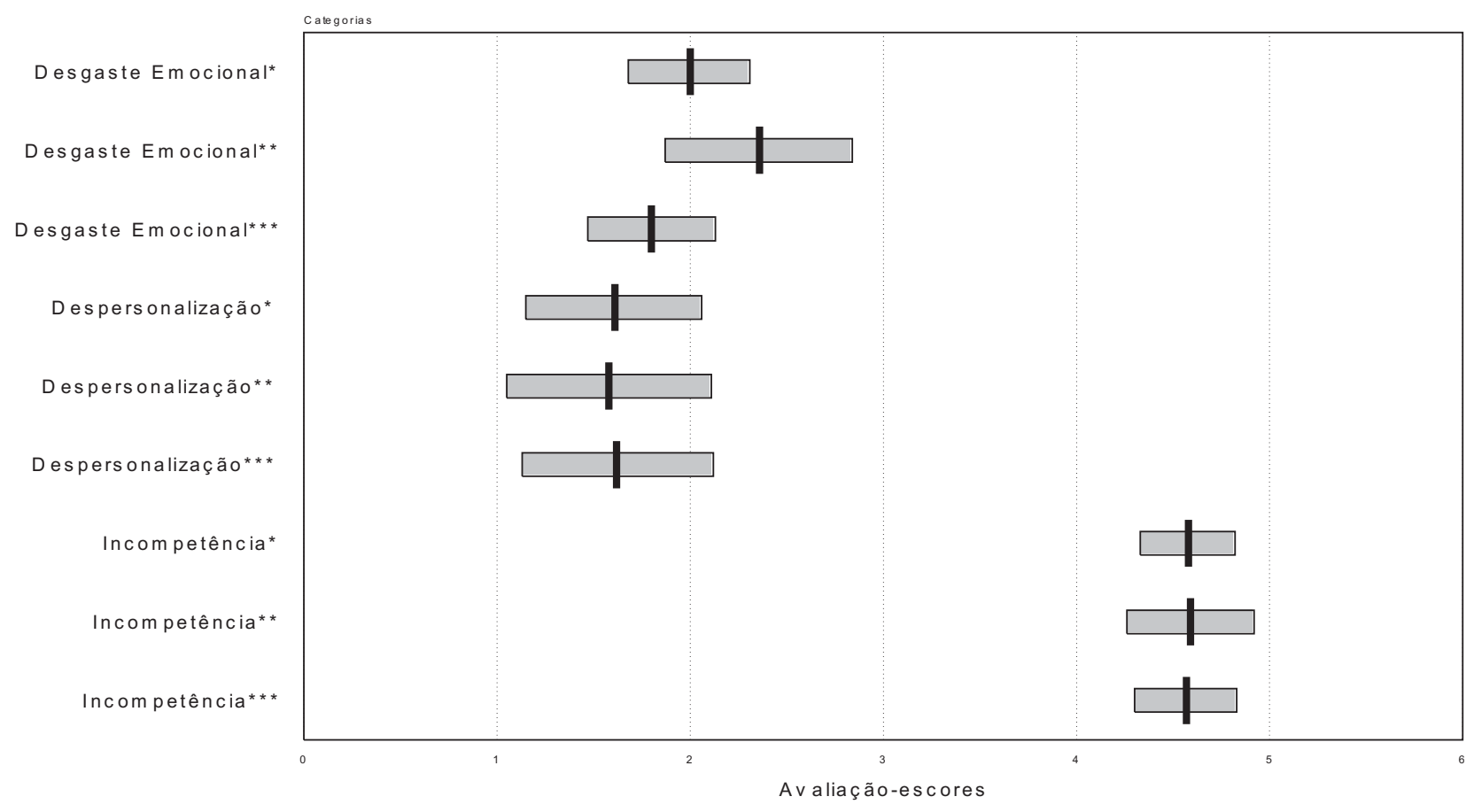

Incompetência é Escore reverso * *Equipe Geral ** Equipe Médica *** Equipe de Enfermagem

Figura 1 - Intervalo da média e desvio padrão da escala de conversão do Inventário de Burnout de Maslach. Ijuí, 2007

Globalmente, a estafa profissional afeta um em cada dois médicos, sendo um terço deles de forma importante e um décimo de forma severa, com características irreversíveis ${ }^{(17)}$. Para os autores, cerca de $40 \%$ a $50 \%$ dos médicos que trabalham com medicina de emergência apresentam níveis elevados de Desgaste Emocional.

Em relação à Despersonalização, observa-se semelhança nos escores das duas categorias, sendo possível considerar um nível baixo de Burnout, porém com heterogeneidade de respostas. Esta semelhança pode ser evidenciada também no que diz respeito à escala Incompetência, porém nesta observa-se afinidade entre as respostas das equipes, com coeficiente de variação baixo.

Quando as pessoas sentem a Exaustão, tende a ser de forma intensa, tanto emocional quanto psicologicamente $^{(12)}$. Elas se sentem exauridas, consumidas e incapazes de reagir por si só e se recuperarem. Quando levantam pela manhã, sentemse quase tão cansadas quanto quando vão se deitar, carecem de energia para iniciar um novo programa de trabalho ou para estar com pessoas. Os autores pontuam que embora inicialmente o Burnout tenha sido percebido como um problema do indivíduo, ou seja, que ele esteja sentindo por alguma falha nas suas 
características pessoais, seu comportamento ou sua produtividade, pesquisas ${ }^{(5,7,12)}$ mostram que o Burnout não é um problema da pessoa, mas do ambiente social no qual ela trabalha. A estrutura de funcionamento, a forma de interação no trabalho, o não reconhecimento do lado humano no trabalho é que parecem conduzir a pessoa a desenvolver a referida síndrome.

Neste contexto, a Síndrome de Burnout surge mais fortemente quando há um desacordo entre a natureza do trabalho e a da pessoa que o executa e este aspecto vem progredindo na medida em que os valores organizacionais parecem se distanciar dos valores pessoais dos trabalhadores. A mesma pode ser percebida, também, como um índice de deslocamento entre o que a pessoa é e o que deve ser, representando uma "erosão nos valores, na dignidade, no espírito e será uma erosão da alma humana ${ }^{(5)}$.

Na Tabela 2, que apresenta a estatística descritiva do Inventário de Burnout de Maslach no Contexto de Trabalho, no que se refere à Ambiguidade de Funções, observa-se clareza da população estudada acerca dos objetivos de seu trabalho, pois a média é alta, demonstrando que estes profissionais a percebem desta forma, diariamente. Nesta variável, evidencia-se uma semelhança de respostas, reafirmando que o papel dos diferentes profissionais encontra-se claramente definido na instituição. A Ambiguidade de Funções surge quando os trabalhadores ou os membros do ambiente de trabalho não têm clareza quanto ao papel que necessitam desempenhar. Ao não conseguir se situar nas tarefas que lhe cabe, o trabalhador poderá vir a ser prejudicado quanto ao seu desempenho. Esta inadequação é fonte de estresse, visto que quando o papel do trabalhador encontra-se claramente definido, isto o ajuda a posicionar-se satisfatoriamente nas diversas situações que envolvem a sua atividade laboral ${ }^{(18)}$.

Possivelmente, estes apontamentos se adequam à forma da instituição onde os pesquisados atuam, de organizar as funções de seus trabalhadores, sem deixar margem para ambiguidade e fornecendo condições para que tenham menor chance de adoecer por estresse crônico.

Tabela 2 - Estatística descritiva do inventário de Burnout de Maslach no contexto de trabalho. Ijuí, 2007

\begin{tabular}{|c|c|c|c|c|c|c|c|c|c|}
\hline \multirow{2}{*}{$\begin{array}{l}\text { Escala de conversão } \\
\text { Contexto de trabalho } \\
\text { Equipe }\end{array}$} & \multicolumn{3}{|c|}{ Média } & \multicolumn{3}{|c|}{ Desvio Padrão } & \multicolumn{3}{|c|}{$\mathrm{CV}(\%)$} \\
\hline & Geral & Enfer. & Médica & Geral & Enfer. & Médica & Geral & Enfer. & Médica \\
\hline Ambiguidade de Funções & 4,63 & 4,494 & 4,856 & 0,25 & 0,401 & 0,163 & 5,35 & 8,93 & 3,37 \\
\hline Estrutura Organizacional & 2,65 & 2,864 & 2,254 & 0,71 & 0,772 & 0,639 & 26,95 & 26,94 & 28,34 \\
\hline $\begin{array}{l}\text { Sobrecarga de Trabalho } \\
\text { (quantitativo) }\end{array}$ & 3,60 & 3,572 & 3,654 & 1,22 & 1,318 & 1,103 & 33,96 & 36,91 & 30,18 \\
\hline $\begin{array}{l}\text { Sobrecarga de Trabalho } \\
\text { (qualitativo) }\end{array}$ & 2,01 & 2,064 & 1,912 & 0,25 & 0,180 & 0,618 & 12,22 & 8,70 & 32,33 \\
\hline $\begin{array}{l}\text { Desenvolvimento da } \\
\text { Carreira }\end{array}$ & 3,20 & 2,966 & 3,616 & 1,18 & 1,218 & 1,221 & 36,81 & 41,05 & 33,78 \\
\hline Relações Interpessoais & 2,26 & 2,330 & 2,144 & 0,33 & 0,494 & 0,207 & 14,44 & 0,494 & 9,66 \\
\hline
\end{tabular}

Ambiguidade de Funções é Escore reverso CV: Coeficiente de variação

Analisando a variável Contexto de Trabalho dos profissionais pesquisados, comparativamente, igualmente emergem algumas similaridades entre equipe de enfermagem e médica, com intervalos de média, desvio padrão e coeficiente de variação.

A Estrutura Organizacional não parece atrapalhar a equipe médica, entretanto aparece com um escore médio para a equipe de enfermagem. Talvez este fato se deva a várias atividades burocráticas e trâmites que devem ser considerados na assistência de enfermagem aos usuários. No que se refere às Relações Interpessoais, evidencia-se semelhança nas respostas e elas, igualmente, revelam um escore baixo, não sendo considerado um dado preocupante.

As relações estabelecidas no contexto de trabalho são relevantes para a saúde do trabalhador, uma vez que este dedica grande parte do seu tempo diário ao desenvolvimento de atividades profissionais $^{(18)}$. O sujeito se reconhece e é reconhecido pela atividade a que se dedica. É uma espécie de segunda via de identificação, na qual a primeira seria 
o nome próprio. Além disso, o trabalho disponibiliza ao sujeito produzir algo e, assim, sentir-se capaz. Ele representa um lugar de relações do indivíduo com o trabalho, com a organização e com os colegas, sendo que boas relações interpessoais são essenciais na prevenção do adoecimento decorrente do trabalho.

A variável Sobrecarga de Trabalho Quantitativa apresenta uma média alta nas duas equipes, com desvio padrão e coeficiente de variação também elevados, demonstrando disparidade entre as percepções. Isso revela que, enquanto uns profissionais sentem que estão trabalhando demais, outros avaliam suas tarefas como manejáveis. Relaciona-se à esta variável a Sobrecarga de Trabalho Qualitativa, que apresenta média baixa nas duas equipes, porém com desvio padrão e coeficiente de variação mais elevados na equipe médica, indicando grande variabilidade nas respostas desta população.

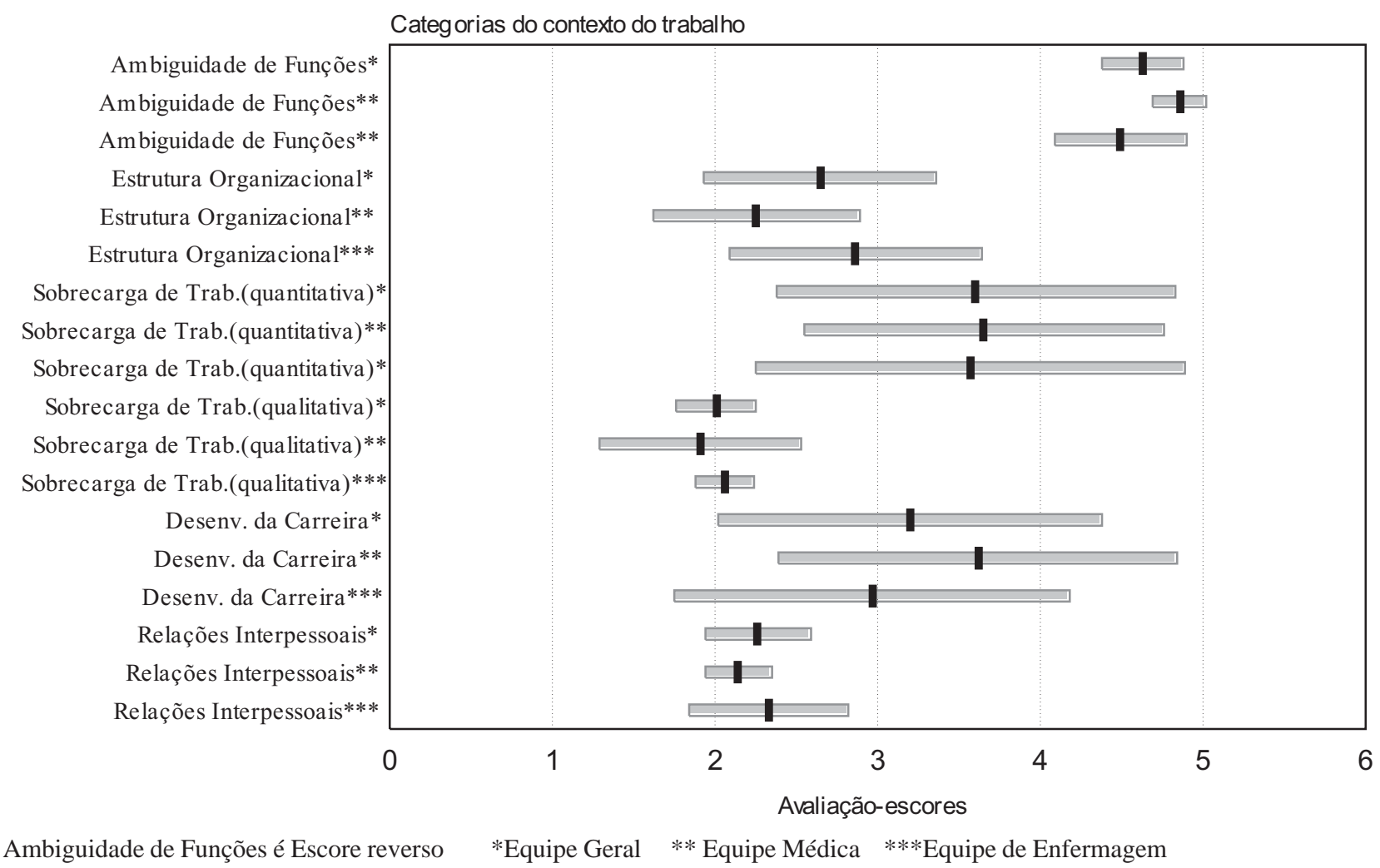

Figura 2 - Intervalo da média e desvio padrão $(\bar{X} \pm S)$ da escala de conversão do Inventário de Burnout de Maslach no contexto de trabalho. Ijuí, 2007

A média de pontuação referente ao Desenvolvimento da Carreira é de 2,97 para a equipe de enfermagem e de 3,62 para a equipe médica, podendo ser este escore considerado médio nas duas categorias profissionais, sendo que apresentam, em ambas, alto desvio padrão e coeficiente de variação. Isto representa posicionamentos individuais diferenciados de cada profissional, demonstrando que alguns sentem que não recebem estímulo para evoluir na instituição onde trabalham. Esses resultados são melhor evidenciados na Figura 2, onde visualiza-se o intervalo da média com mais e menos um desvio padrão.

Analisando os dados obtidos com a comparação das variáveis da Síndrome de Burnout nas equipes médica e de enfermagem, constata-se que elas estão presentes em ambas, em pequena proporção. As médias mais elevadas são referentes à Sobrecarga de Trabalho Quantitativa e Desenvolvimento da Carreira, que são questões merecedoras de reflexões e de ações direcionadas à minimização do estresse ocupacional e, consequentemente, na prevenção da Síndrome de Burnout.

\section{CONCLUSÕES}

Observa-se o impacto da ciência e da tecnologia nas relações profissionais e sociais dos trabalhadores e, de um modo particular, sobre os profissionais da saúde. As mudanças no processo de trabalho estão afetando diretamente a vida do trabalhador, podendo 
causar prejuízos à sua saúde, ao seu desempenho no trabalho e, consequentemente, à instituição.

As exigências que o mercado de trabalho está impondo ao trabalhador estão, em algumas situações, levando ao sofrimento psíquico. O trabalhador da saúde, especificamente, está exposto a inúmeros estressores no ambiente de trabalho que influenciam no seu desempenho, tanto pessoal, quanto social e organizacional, podendo contribuir para o desencadeamento de doenças.

Avaliando as três dimensões da Síndrome de Burnout, o Desgaste Emocional, a Despersonalização e a Incompetência, pode-se afirmar que os escores obtidos foram baixos nas duas primeiras e elevados na Incompetência (escore reverso), indicando baixo nível de Burnout nos profissionais. Ainda, destaca-se a homogeneidade das respostas, confirmada pelo coeficiente de variação, menor que $30 \%$. Ressalta-se que na análise comparativa entre equipe médica e de enfermagem o Desgaste Emocional apresentou média mais alta na equipe médica e as outras dimensões apresentaram semelhança nas duas categorias.

Dentre as variáveis relacionadas ao Contexto do Trabalho, as que apresentaram médias mais elevadas foram a Sobrecarga de Trabalho, em sua análise quantitativa, o Desenvolvimento da Carreira e a Estrutura Organizacional, tanto para a equipe de enfermagem quanto para a médica, evidenciando sintomas da síndrome. Ambigüidade de Funções, Sobrecarga de Trabalho Qualitativa e Relações Interpessoais apresentaram médias baixas, porém igualmente merecedoras de atenção por parte dos líderes da instituição, pois são fundamentais na sintonia das equipes no ambiente de trabalho.

Os profissionais pesquisados mostraram em suas respostas escores máximos e mínimos no mesmo instrumento, evidenciando o quanto as características individuais, sociais e culturais estão implicadas no surgimento da Síndrome de Burnout. Entende-se, a partir da interpretação dos resultados, que as variáveis da síndrome estão interligadas, sendo que a constatação de uma característica pode evoluir para o desencadeamento de outros sintomas. Ela é silenciosa, sua instalação é lenta e progressiva, com intensidade de sintomas variável.

Conclui-se que os profissionais que atuam na unidade pesquisada apresentam alguns sintomas de Burnout, daí a necessidade de estratégias de enfrentamento adequadas, visando minimizar os estressores e melhorar a qualidade de vida dos trabalhadores, indo além da educação continuada. $\mathrm{O}$ fato de ser uma instituição nova, com profissionais também jovens e já com alguns sintomas de Burnout justifica esta postura. Para tanto, os estressores devem ser encarados como desafios, buscando-se estratégias que sejam capazes de minimizá-los. Também, acrescenta-se que é importante, neste contexto, o entendimento pessoal de cada trabalhador acerca da sua atividade e do significado dela no todo da instituição.

\section{REFERÊNCIAS}

1. Deslandes SF. Violência no cotidiano dos serviços de emergência hospitalar: Representações, práticas, interações e desafios [tese]. Rio de Janeiro (RJ): Escola Nacional de Saúde Pública, Fundação Oswaldo Cruz; 2000.

2. Stacciarini JMR, Tróccol BT. O estresse na atividade ocupacional do enfermeiro. Rev Latino-Am Enferm. 2001 Mar; 9(2):17-25.

3. Stumm EMF, Oliveski CC, Costa CFL, Kirchner RM, Silva LAA. Estressores e coping vivenciados por enfermeiros em um serviço de atendimento préhospitalar. Cogitare Enferm. 2008; Jan/Mar;13(1):33-43

4. Codo W, coordenador. Educação: carinho e trabalho. Petrópolis: Vozes; 1999.

5. Maslach C, Leiter MP. Trabalho: fonte de prazer ou desgaste? Guia para vencer o estresse na empresa. Campinas: Papirus; 1999.

6. Guimarães LAM, Grubits S. Série saúde mental e trabalho. São Paulo: Casa do Psicólogo; 2004.

7. Benevides-Pereira AMT. O Estado da Arte do Burnout no Brasil. Rev Eletron InterAção Psy. 2003;1(1):4-11.

8. Pizzoli LML. Qualidade de vida no trabalho: um estudo de caso das enfermeiras do Hospital Heliópolis. Ciênc Saúde Col. 2005;10(4):1055-62.

9. Pitta A. Hospital: dor e morte como ofício. São Paulo: Hucitec; 1999.

10. Feliciano KVO, Kovacs MH, Sarinho SW. Sentimentos de profissionais dos serviços de pronto-socorro pediátrico: reflexões sobre Burnout. Rev Bras Saude Mater Infant. 2005 Jul/Set; 5(3):319-27.

11. Rosa C, Carlotto MS. Síndrome de Burnout e satisfação no trabalho em profissionais de uma instituição hospitalar. Rev SBPH. 2005 Dez;8(2):1-15 
12. Maslach C, Jackson S, Leiter M. Maslach Burnout Inventory. In: Zalaquet C, Wood R, organizadores. Scarecrow Evaluating Stress: Lanham (Md); 1997.

13. Lautert L. O desgaste profissional do enfermeiro [tese]. Salamanca: Universidade Pontífica de Salamanca; 1995.

14. Carlotto MS, Nakamura AP, Câmara SG. Síndrome de Burnout em estudantes universitários da área da saúde. PSICO. 2006;37(1):57-62.

15. Carlotto MS, Gobbi MD. Síndrome de Burnout: um problema do indivíduo ou de seu contexto de trabalho? Rev Aletheia. 2000 Jul/Dez; 10:103-14.

16. Fonseca AM, Soares E. Desgaste emocional: depoimentos de enfermeiros que atuam no ambiente hospitalar. Rev René. 2006;7(1):91-7.

17. Giglio AD, Tucunduva LTCM, Garcia AP, Prudente FVB, Centofanti G, Souza CM, et al. A síndrome da estafa profissional em médicos cancerologistas brasileiros. Rev Assoc Méd Bras. 2006; 52(2): 108-12.

18. Limongi-França AC, Rodrigues AL. Stress e trabalho: guia básico com abordagem psicossomática. $3^{\mathrm{a}}$ ed. São Paulo: Atlas; 2002. 